\title{
Formulasi Krim Ekstrak Etanol Kulit Batang Faloak (Sterculia Quadrifida R.Br)
}

\author{
Rosalia Mektildis \\ Farmasi Poltekkes Kemenkes Kupang \\ e-mail: rosaliamektildis@gmail.com
}

\begin{abstract}
ABSTRAK
Faloak (Sterculia quadrifida R.Br) merupakan salah satu tanaman khas di Nusa Tenggara Timur yang bagian kulit batangnya sering dimanfaatkan dalam pengobatan karena memiliki beberapa kandungan berkhasiat salah satunya flavonoid. Tujuan dilakukan penelitian untuk mendapatkan formulasi krim ekstrak etanol kulit batang faloak (Sterculia quadrifida $R . B r$ ) yang memenuhi karakteristik krim. Ekstraksi dilakukan dengan perkolasi menggunakan etanol $70 \%$ yang kemudian dipekatkan untuk mendapatkan ekstrak kental. Ekstrak kental sebanyak 2\% digunakan dalam tiga formulasi krim yang berbeda. Pengujian sifat fisik dan stabilitas terhadap formula krim meliputi uji stabilitas selama 4 minggu dengan parameter uji yaitu pengamatan organoleptis, uji viskositas, daya sebar, homogenitas, $\mathrm{pH}$ dan tipe krim.

Penelitian yang dilakukan diperoleh hasil, terjadi perubahan organoleptis dari perubahan warna menjadi coklat pada formula 1 dan 2 dan perubahan bentuk pada formula 3 , tidak terjadi perubahan bau ketiga formula. Uji homogenitas, formula 1 dan formula 2 homogen sedangkan formula 3 tidak homogen. Daya sebar dari ketiga formula cenderung mengalami penurunan tetapi formula 2 memenuhi persyaratan daya sebar $5-7 \mathrm{~cm}$. pH dari ketiga formula krim 5. Berdasarkan nilai syarat viskositas yaitu 2000-50000 cps maka yang memenuhi persyaratan viskositas adalah formula 2 kecepatan $20 \mathrm{rpm}$ dan formula 3, jadi disimpulkan formula 2 memenuhi persyaratan karakterisasi krim ekstrak etanol kulit batang faloak (Sterculia quadrifida R.Br).
\end{abstract}

Kata kunci : Krim ekstrak faloak, Karakteristik krim

\section{PENDAHULUAN}

Faloak (Sterculia quadrifida

R.Br) merupakan salah satu tumbuhan khas NTT yang banyak pemanfaatannya dalam pengobatan. Kulit pohon faloak mengandung senyawa fenolik, flavonoid, alkaloid dan terpenoid. Secara turun temurun faloak telah dimanfaatkan masyarakat Nusa Tenggara Timur khususnya di Kota Kupang dan sekitarnya untuk menyembuhkan berbagai penyakit antara lain kulit pohon 
faloak dapat menyembuhkan penyakit tifus, maag, dan lever. Faloak juga digunakan sebagai peluruh haid, peluruh sisa-sisa kotoran setelah melahirkan, dan pemulihan setelah melahirkan (Siswadi dkk., 2013). Berdasarkan penelitian yang dilakukan oleh Malese (2014), kulit pohon faloak menunjukkan aktivitas antioksidan sangat kuat.

Penelitian oleh Hilaria,dkk 2016, tanaman lelak memiliki aktivitas antioksidan dengan $\mathrm{IC}_{50}$ $87,292 \mu \mathrm{g} / \mathrm{ml}$ memiliki kandungan aktif yang mirip dengan kulit faloak. Tanaman jahe merah memiliki aktivitas antioksidan dengan konsentrasi $30,40,50,60$ dan $70 \mathrm{ppm}$ memiliki nilai $\mathrm{IC}_{50}$ 41,27 ppm (Yuliani, Sambara, \& Mau, 2016).

Bagian pohon faloak yang cukup tinggi dimanfaatkan selama ini adalah bagian kulit yang dimanfaatkan sebagai obat (Ranta, 2011). Pemanfaatan kulit batang Faloak dapat dilakukan dengan metode ekstraksi.

Ekstraksi kulit batang Faloak dapat dilakukan dengan cara perkolasi menggunakan pelarut etanol $70 \%$. Pelarut etanol $70 \%$ digunakan karena zat yang akan ditarik merupakan senyawa flavonoid (Salisburydan Ross, 1995). Ekstrak etanol kulit batang faloak dalam penelitian ini dibuat sediaan krim

Krim merupakan salah satu sediaan kosmetik yang sering digunakan. Menurut Ansel (1989), krim didefinisikan sebagai "cairan kental atau emulsi setengah padat baik bertipe air dalam minyak atau minyak dalam air." Banyak dokter dan pasien lebih suka pada krim daripada salep untuk satu hal, umumnya mudah menyebar rata dan dalam hal krim dari emulsi jenis minyak dalam air lebih mudah dibersihkan daripada kebanyakan salep.

Komponen krim terdiri dari bahan dasar, bahan aktif dan bahan tambahan. Bahan dasar terdiri dari fase minyak, fase air dan emulgator atau surfaktan. Emulgator dan surfaktan berfungsi untuk menurunkan tegangan permukaan antara 
kedua fase yang tidak saling bercampur, sedangkan bahan tambahannya dapat meliputi pengawet, pengkhelat, pelembab, pewarna dan pewangi (Kurniati, 2011). Untuk menjamin krim yang dibuat memenuhi standar maka dilakukan uji sifat fisik dan stabilitas.

Stabilitas didefenisikan sebagai kemampuan suatu produk obat atau kosmetik untuk bertahan dalam batas spesifikasi yang diterapkan sepanjang periode penyimpanan dan penggunaan untuk menjamin identitas, kekuatan, kualitas dan kemurnian produk. Defenisi sediaan kosmetik yang stabil yaitu suatu sediaan yang masih berada dalam batas yang dapat diterima selama periode waktu penyimpanan dan penggunaan, dimana sifat dan karakteristiknya sama dengan yang dimiliki saat dibuat. Ketidakstabilan fisika dari sediaan emulsi atau krim ditandai dengan adanya pemucatan warna atau munculnya warna, timbulnya bau, perubahan atau pemisahan fase, pecahnya emulsi, pengendapan atau caking, perubahan konsistensi, pertumbuhan kristal, terbentuknya gas dan perubahan fisik lainnya (Anonim, 2005), maka dibutuhkan uji pada sediaan krim meliputi uji organoleptis, homogenitas, daya sebar, $\mathrm{pH}$, viskositas dan pemeriksaan stabilitas

\section{METODE}

\section{Alat dan Bahan}

Alat yang digunakan dalam penelitian ini meliputi : mortir dan stamper, penangas air (Memmert), Alat gelas (IwakiPyrex), sendok tanduk, spatel, pipet, timbangan digital (Shimadzu), rangkaian perkolator, kertas $\mathrm{pH}$, kertas perkamen, kertas saring, hot plate, oven (Wtb Binder) dan viskometer (Wagtech).

Bahan yang digunakan dalam penelitian ini sebagai berikut: Ekstrak kental kulit batang faloak (Stercullia sp.), etanol $\quad 70 \% \quad$ (One-med), aquadest, asam stearat, 
trietanolamin, parafin cair,

Perhitungan

rendemen

gliserin, metil paraben, propil

menggunakan

rumus

paraben, setil alkohol, propilen

glikol, adeps lanae, vitamin $\mathrm{E}$ dan

oleum rosa.

$\%$ Rendemen $=$

$\frac{\text { bobot ekstrak }}{\text { bobotsimplisia }}$ X 100\%

(1)

\section{Pembuatan krim ekstrak etanol kulit batang faloak}

\section{Ekstraksi kulit batang faloak}

Kulit batang faloak diambil

di daerah Jalur 40 Bolok-Kupang, kemudian dibersihkan, dicuci, dirajang, dikeringkan dengan cara diangin-anginkan dan diserbukkam. Simplisia yang telah diserbukkan ditimbang 200 gram, basahi serbuk dengan 100 $\mathrm{mL}$ cairan penyari etanol $70 \%$ dan didiamkan selama 3 jam kemudian ke dalam perkolator, setelah 24 jam kran perkolator dibuka dan biarkan cairan tersebut menetes dengan kecepatan $1 \mathrm{~mL} /$ menit. Cairan penyari ditambahkan secara kontinyu hingga selalu selapis di atas permukaan serbuk simplisia. Ekstrak yang diperoleh dipekatkan dengan evaporator pada suhu $50^{\circ} \mathrm{C}$, setelah itu diuapkan di atas tangas air untuk mendapat ekstrak kental.

Cara pembuatan krim menurut Syamsuni (2006) yaitu bagian lemak dilebur di atas tangas air kemudian tambahkan bagian airnya dengan zat pengemulsi, aduk sampai terjadi suatu campuran yang berbentuk krim.

Bahan yang terdapat dalam formula (Tabel I) dibagi menjadi 2 kelompok yaitu fase minyak dan fase air. Fase minyak dicampurkan pada suhu $70^{\circ} \mathrm{C}$ (campuran pertama), dan dan fase air dicampur (campuran kedua). Campuran pertama dimasukkan ke dalam mortir yang telah dipanaskan terlebih dahulu. Campuran diaduk hingga homogen dan membentuk massa krim. Kemudian masukkan campuran kedua sedikit demi sedikit sambil digerus hingga 
homogen. Setelah mortir dingin tocopherol, gerus hingga tambahkan ekstrak, selanjutnya homogen. Tambahkan oleum gerus sampai diperoleh krim yang homogen. Tambahkan $d-\alpha$ rosae, aduk krim hingga homogen.

Tabel I. Formula krim ekstrak etanol kulit batang faloak

\begin{tabular}{llll}
\hline \multicolumn{1}{c}{ Nama bahan } & \multicolumn{3}{c}{ Formula (gram) } \\
& $\mathrm{F} 1$ & $\mathrm{~F} 2$ & $\mathrm{~F} 3$ \\
\hline Ekstrak kental kulit batang faloak & $2 \%$ & $2 \%$ & $2 \%$ \\
Asam stearat & 10 & 12 & 29 \\
Setil alkohol & 6 & 6 & - \\
Trietanolamin & 2 & 4 & 3 \\
Parafin cair & 20 & - & 50 \\
Gliserin & 20 & - & - \\
Propilen glikol & - & 20 & - \\
Adeps lanae & - & 4 & 6 \\
Metil paraben & 0,1 & 0,2 & 0,1 \\
Propil paraben & 0,1 & 0,02 & 0,05 \\
Vitamin E (d- $\alpha$-tokoferol) & 0,05 & 0,05 & 0,05 \\
Pewangi & $\mathrm{Qs}$ & $\mathrm{Qs}$ & $\mathrm{Qs}$ \\
Aquadest & $\mathrm{ad} \mathrm{100}$ & $\mathrm{ad} \mathrm{100}$ & $\mathrm{ad} \mathrm{100}$ \\
\hline
\end{tabular}

\section{Pengujian sediaan krim}

Dilakukan berbagai pengujian pada krim ekstrak etanol kulit batang Faloak (Sterculia quadrifida $R . B r$ ) yaitu uji karakterisasi dan uji stabilitas. Pemeriksaan uji karakterisasi yaitu uji organoleptik: memperhatikan bentuk, warna dan bau dari sediaan krim yang dibuat;

Pemeriksaan homogenitas : sediaan ditimbang $0,1 \mathrm{~g}$ kemudian dioleskan secara merata dan tipis pada kaca. Krim harus menunjukkan susunan yang homogen dan tidak terlihat adanya butiran halus (Anonim, 1985); Pemeriksaan $\mathrm{pH}$ : menggunakan kertas $\mathrm{pH}$ indikator universal; Uji tipe emulsi krim : Kedalam sedikit sampel emulsi ditambahkan sedikit air, dan dilakukan pengocokan atau pengadukan. Jika diperoleh kembali emulsi homogen, maka emulsi yang diuji berjenis $M / A$. 
Jika sampel dicampur dalam minyak, maka akan menyebabkan pecahnya emulsi. Pada jenis $\mathrm{A} / \mathrm{M}$ akan diperoleh hasil yang sebaliknya (Voight, 1995); Pemeriksaan daya sebar : uji menggunakan sepasang lempeng kaca dan anak timbang gram. Krim ditimbang $\pm 0,5 \mathrm{~g}$, diletakkan di tengah kaca, di atas kaca diberi anak timbang sebagai beban dan dibiarkan 1 menit. Pemeriksaan viskositas : Uji viskositas krim dilakukan dengan menggunakan alat viscometer, menggunakan rotor nomor 6 dengan kecepatan $20 \mathrm{rpm}$. Diameter krim yang menyebar diukur kemudian ditambahkan beban $50 \mathrm{~g}, 100 \mathrm{~g}, 150 \mathrm{~g}$ dan 200 g sebagai beban tambahan, setiap penambahan beban didiamkan setelah 1 menit dan dicatat diameter krim yang menyebar seperti sebelumnya (Fujiastuti dan Sugihartini, 2015. Pemeriksaan stabilitas krim krim meliputi bentuk, bau, warna, $\mathrm{pH}$, homogenitas, daya sebar tipe emulsi dan dievaluasi pada suhu $40 \pm 2^{\circ} \mathrm{C}, 27-28^{\circ} \mathrm{C}$ dan $4-8^{\circ} \mathrm{C}$ selama 4 minggu dengan pengamatan setiap minggu sekali (Anonim, 2013).

\section{Analisis Hasil}

Data hasil pengamatan terhadap karakteristik krim ekstrak etanol kulit batang faloak dan stabilitas dianalisis secara deksriptif kualitatif. Krim dinyatakan memenuhi karakteristik krim apabila krim tersebut stabil selama penyimpanan dan memenuhi uji organoleptis dengan tidak ada perubahan warna, bau dan bentuk, memiliki pH 4,5-6,5, tidak mengalami perubahan tipe krim, memiliki viskositas pada rentang 2000-50000 cPs, homogen : jika saat dioleskan pada kaca tidak ada butiran halus yang terlihat, dan berdaya sebar 5-7 cm. Krim dikatakan memenuji uji stabilitas fisik jika tidak terjadi perubahan selama penyimpanan pada suhu tinggi, suhu ruang dan suhu rendah.

\section{HASIL DAN PEMBAHASAN \\ HASIL}

Ekstraksi 
Ekstrak kental yang diperoleh dari proses ekstraksi dengan metode perkolasi dari perkolat dengan warna ekstrak kental coklat tua dan berbau khas ekstrak dengan persen rendemen yang diperoleh sebesar $13,44 \%$.

\section{Formulasi krim ekstrak etanol Kulit Batang Faloak}

Krim ekstrak etanol kulit batang faloak dibuat sebanyak tiga formula yang berbeda dan untuk tiap formula dilakukan 3 replikasi. Tiap replikasi kemudian dibagi menjadi 3 untuk penyimpanan suhu tinggi, suhu ruang, dan suhu rendah sehingga jumlah sediaan semuanya menjadi 9 sediaan untuk tiap formula. Setelah terbentuk sediaan krim, dilakukan uji karakterisasi terhadap krim
Karakteristik Krim Ekstrak Etanol Kulit Batang Faloak

Pengamatan yang dilakukan terhadap krim yaitu stabilitas krim dengan melakukan pengamatan organoleptis (bentuk, warna dan bau), homogenitas, $\mathrm{pH}$, tipe krim, daya sebar, dan viskositas. Pengujian stabilitas krim dilakukan untuk mengetahui sebuah sediaan dapat bertahan dan tidak mengalami kerusakan apabila disimpan pada suhu ekstrim seperti pada suhu rendah, suhu kamar dan suhu tinggi dalam jangka waktu tertentu. Pengujian stabilitas krim bertujuan untuk mengetahui lama waktu sebuah sediaan dapat bertahan saat berada di pasaran dan saat digunakan konsumen. Pengujian stabilitas dan karakteristik krim dapat dilihat pada Tabel II dan III.

Tabel II. Hasil uji krim ekstrak etanol kulit batang Faloak 3 replikasi selama 4 Minggu

\begin{tabular}{lccccccccc}
\hline \multicolumn{1}{c}{$\begin{array}{c}\text { Jenis } \\
\text { Pengujian }\end{array}$} & \multicolumn{3}{c}{$\begin{array}{c}\text { Formula 1 } \\
\text { Suhu }\end{array}$} & \multicolumn{4}{c}{$\begin{array}{c}\text { Formula 2 } \\
\text { Suhu }\end{array}$} & \multicolumn{3}{c}{$\begin{array}{c}\text { Formula 3 } \\
\text { Suhu }\end{array}$} \\
\cline { 2 - 4 } & Tinggi & Ruang & Rendah & Tinggi & Ruang & Rendah & Tinggi & Ruang & Rendah \\
\hline Bentuk & SP & SP & SP & SP & SP & SP & SP & SP & SP \\
$\begin{array}{l}\text { Warna } \\
\text { Bau }\end{array}$ & MM $^{*}$ & MM $^{*}$ & MM $^{*}$ & MM & MM & MM & MM $^{*}$ & MM $^{*}$ & MM $^{*}$ \\
$\begin{array}{l}\text { Homoge- } \\
\text { nitas }\end{array}$ & H & TT & TT & TT & TT & TT & TT & TT & TT \\
pH & 5 & 5 & 5 & 5 & 5 & 5 & 5 & 5 & 5
\end{tabular}




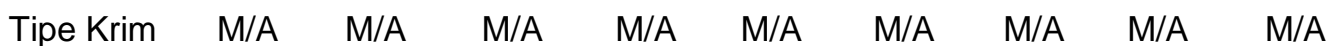
Daya $\quad 5,55-\quad 4,01-\quad 5,17-\quad 5,77-\quad 5,17-\quad 5,50-\quad 3,95-\quad 2,55-\quad 3,88-$

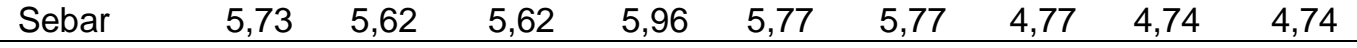
(Sumber : Data Primer Penelitian, 2016).

Keterangan : $\mathrm{SP}=$ Semi Padat; $\mathrm{MM}=$ Merah Muda; $\mathrm{MM}^{*}=$ Terjadi perubahan dari merah muda menjadi Coklat, TT=Tidak tengik, $\mathrm{H}$ : Homogen, M/A : Tipe Minyak dalam Air.

Tabel III. Hasil Uji Viskositas Krim Ekstrak Etanol kulit batang Faloak

\begin{tabular}{|c|c|c|c|c|c|}
\hline Formula & $\begin{array}{c}\text { Replikasi } \\
1\end{array}$ & $\begin{array}{c}\text { Replikasi } \\
2\end{array}$ & $\begin{array}{c}\text { Replikasi } \\
3\end{array}$ & $\begin{array}{l}\text { Rata- } \\
\text { Rata }\end{array}$ & KET \\
\hline 1 & $\begin{array}{c}\text { Tidak } \\
\text { Terbaca }\end{array}$ & $\begin{array}{c}\text { Tidak } \\
\text { Terbaca }\end{array}$ & $\begin{array}{c}48703 \\
\text { cps }\end{array}$ & $\begin{array}{c}48703 \\
\text { cps }\end{array}$ & $\begin{array}{l}\text { Memenuhi } \\
\text { Syarat }\end{array}$ \\
\hline 2 & $24494 \mathrm{cps}$ & $27448 \mathrm{cps}$ & $\begin{array}{c}32694 \\
\text { cps }\end{array}$ & $\begin{array}{l}28212 \\
\text { cps }\end{array}$ & $\begin{array}{c}\text { Memenuhi } \\
\text { Syarat }\end{array}$ \\
\hline 3 & $4460 \mathrm{cps}$ & $6122 \mathrm{cps}$ & $\begin{array}{c}11045 \\
\text { cps }\end{array}$ & $\begin{array}{l}7209 \\
\text { cps }\end{array}$ & $\begin{array}{c}\text { Memenuhi } \\
\text { Syarat }\end{array}$ \\
\hline
\end{tabular}

(Sumber : Data Primer Penelitian, 2016).

\section{PEMBAHASAN}

\section{Ekstraksi}

Persen rendemen ekstrak etanol kulit batang faloak terdapat perbedaan bila dibandingkan dengan persen rendemen ekstrak etanol kulit batang faloak pada penelitian sebelumnya yang dilakukan oleh Malese (2014) dimana diperoleh persen rendemen sebesar $17,89 \%$. Hal tersebut dapat disebabkan oleh tingkat kekentalan ekstrak yang berbeda. Perkolasi dipilih dalam melakukan ekstraksi karena salah satu zat aktif yang terkandung dalam kulit batang faloak yaitu flavonoid yang bersifat tidak tahan panas dan proses perkolasi dapat menarik zat aktif lebih baik karena saat proses perkolasi telah terjadi maserasi tahap banyak dengan cairan penyari yang mengalir terus menerus dengan kecepatan yang tidak terlalu cepat atau lambat sehingga diharapkan hasil yang didapat optimal. Cairan penyari yang digunakan yaitu etanol karena pelarut etanol $70 \%$ dapat menarik zat aktif tertentu (alkaloida basa, minyak 
menguap, glikosida, kurkumin, kumarin, antrakinon, flavonoid, steroid, damar dan klorofil, lemak, malam, tanin dan saponin hanya sedikit larut), daya tarik zat aktif yang lebih baik dimana bahan pengotor hanya dalam skala kecil turut dalam cairan pengekstraksi serta memiliki harga yang cukup terjangkau.

\section{Formulasi krim ekstrak etanol Kulit Batang Faloak}

Krim ekstrak etanol kulit batang faloak dibuat sebanyak tiga formula yang berbeda dan untuk tiap formula dilakukan 3 replikasi. Basis yang digunakan tiap formula terdapat perbedaan yang dimaksudkan agar dapat membedakan dan melihat formula yang paling baik dari ketiga formula yang digunakan.

\section{Karakteristik Krim Ekstrak Etanol Kulit Batang Faloak}

Hasil pengamatan

organoleptis krim untuk formula 1, 2 dan 3 (lihat tabel II) bentuk krim tetap semipadat dan tetap berbau khas oleum rosa atau tidak berbau tengik. Namun pada formula 3 baik replikasi 1, 2 dan 3 memiliki bentuk yang lebih encer dibandingkan formula lain yang disebabkan karena fase air yang sedikit sehingga tidak membentuk massa krim yang cukup kental. Warna krim yang dihasilkan pada awal pembuatan krim yaitu merah muda namun setelah disimpan dari minggu ke1 hingga minggu ke-4 terjadi perubahan warna krim menjadi coklat untuk formula 1 pada suhu kamar dan suhu tinggi dan pada formula 2 baik suhu rendah, suhu kamar maupun suhu tinggi sedangkan formula 3 terjadi perubahan warna menjadi coklat tua pada suhu tinggi. Perubahan warna krim yang menjadi coklat dikarenakan adanya trietanolamin yang merupakan suatu amin yang bersifat basa kuat dengan flavonoid yang merupakan senyawa fenol sehingga warnanya berubah bila bereaksi dengan basa.

Pengamatan homogenitas bertujuan untuk mengetahui apakah semua zat sudah 
tercampur merata sehingga apabila diaplikasikan ke bagian kulit yang membutuhkan semua bagian kulit memiliki kesempatan yang sama untuk mendapat khasiat dari zat yang terkandung dalam suatu sediaan. Homogenitas dari ketiga formula dari ketiga tempat penyimpanan mulai dari minggu ke-0 hingga minggu ke-4, untuk formula 1 dan 2 terlihat homogen tetapi formula 3 tidak homogen yang disebabkan karena fase minyak pada formula 3 yang lebih banyak dibandingkan dengan fase air sehingga tidak tercampur meratadan tidak membentuk massa krim yang baik. Formula 3 sampai pada minggu ke-4 semakin terlihat jelas tidak homogen karena terlihat menggumpal dan cairan minyak yang memisah.

Pengujian tipe krim dilakukan dengan dua cara yaitu pengenceran dengan air dan dengan pewarnaan. Dengan metode pengenceran, krim dari minggu awal setelah pembuatan krim hingga minggu ke-4 ketiga formula larut dengan air. Begitu pun dengan pewarnaan menggunakan metilen biru ketiga formula menjadi biru maka ketiga formula tidak mengalami perubahan tipe krim, tetap bertipe minyak dalam air. Krim termasuk suatu emulsi yang memiliki dua tipe yaitu air dalam minyak dan minyak dalam air. Penentuan tipe krim dilakukan karena pada umumnya untuk tujuan kosmetik tipe yang lebih cocok untuk krim yakni bertipe minyak dalam air salah satunya karena mudah tercuci air sehingga mudah digunakan. Emulsi yang baik tidak mengalami perubahan tipe sehingga dilakukan pengujian tipe krim selama penyimpanan.

Hasil pengujian $\mathrm{pH}$ dari awal setelah pembuatan krim hingga pada minggu ke empat adalah $\mathrm{pH}$ 5 tidak terjadi perubahan dan memenuhi persyaratan $\mathrm{pH} 4,5-$ 6,5 (Tranggono dan Latifah, 2007). Pengukuran pH krim dilakukan untuk mengetahui apakah krim memiliki $\mathrm{pH}$ yang sesuai dengan $\mathrm{pH}$ kulit sehingga 
tidak terlampau asam atau basa agar tidak merusak kulit (Anief, 2010).

Pengujian daya sebar
bertujuan untuk melihat
kemampuan menyebar sediaan
di atas permukaan kulit 1995). Kemampuan menyebar krim yang baik akan memberikan kemudahan pengaplikasian pada permukaan kulit. Selain itu penyebaran zat aktif pada kulit akan lebih merata sehingga efek yang ditimbulkan zat aktif menjadi lebih optimal. Semakin besar daya sebar krim semakin baik karena semakin luas juga kontak antara kulit dan krim sehingga zat aktif yang terkandung dapat menyebar dengan baik dan merata

\section{SIMPULAN}

Berdasarkan hasil penelitian yang telah dilakukan dapat disimpulkan bahwa formula 2 memenuhi uji stabilitas dengan parameter uji meliputi pengamatan organoleptis meliputi warna coklat, bau tidak tengik dan bentuk semi padat, uji homogenitas tidak terdapat partikel kasar, uji daya sebar 5-7 $\mathrm{cm}$, uji $\mathrm{pH}$ 4,5-6,5 dan tipe krim minyak dalam air dan memiliki viskositas yang sesuai persyaratan diantara 2000 50000 cps.

\section{DAFTAR PUSTAKA}

Anief, M. 2010. IImu Meracik Obat. Gadjah Mada University Press. Yogyakarta.

Anonim. 1985. Formularium Kosmetika Indonesia. Departemen Kesehatan RI. Jakarta. 2005. Asean Guideline on Stability of Drug Product. 9t $^{\text {th }}$ ACCSQ-PPWQ Meeting, Philipines, 21-24 Feb 2005. 2013. Asean Guideline on Stability Study of Drug Product.

Ansel, H. C. 1989. Pengantar Bentuk Sediaan Farmasi. Diterjemahkan oleh Farida Ibrahim. Penerbit Universitas Indonesia. Jakarta.

Fujiastuti, T., dan Sugihartini, N. 2015. Sifat Fisik dan Daya Iritasi Gel Ekstrak Etanol Herba Pegagan (Centella asiatica L.) dengan Variasi 
Jenis Gelling Agent. Pharmacy.12. hal. 11-20

Kurniati, N. 2011. Uji Stabilitas Fisik dan Aktivitas Antioksidan Formula Krim Mengandung Ekstrak Kulit Buah Delima (Punica granatum L). Skripsi. Universitas Indonesia. Jakarta.

Malese, S. A. 2014. Uji Aktivitas Antioksidan Ekstrak Etanol Kulit Pohon Faloak (Sterculia comosa Wallich) dengan metode DPPH $(1,1$ difenyl-2-picrylhydrazyl).

Karya Tulis IImiah. Jurusan Farmasi Poltekkes Kemenkes Kupang. Kupang.

Ranta, F. 2011. Sifat Antimikroba Zat Ekstraktif Pohon Faloak (Sterculia comosa Wallich). Tesis. Sekolah Pascasarjana Institut Pertanian Bogor. Bogor

Syamsuni, H.A. 2006. IImu Resep. EGC. Jakarta.

Siswadi dan Heny R. 2013. Variasi Morfologi Faloak (Sterculia quadrifida R.Br) dari Tiga Populasi Asal Nusa Tenggara Timur. Prosiding Seminar Nasional Silvikultur II. hal. 369-374. Fakultas Kehutanan Universitas Gadjah Mada. Yogyakarta.

Salisbury, F. B., dan Ross, C. W. 1995. Fisiologi Tumbuhan. Jilid 2. Diterjemahkan oleh
Lukman, R. D., dan Sumaryono. Penerbit ITB Bandung. Bandung.

Tranggono, R.I., dan Latifah, F. 2007. Buku Pegangan IImu Pengetahuan Kosmetik. Penerbit Pustaka Utama. Jakarta Voigt, R. 1995. Buku Pelajaran Teknologi Farmasi. Diterjemahkan oleh Soendani Noerono.Gadjah Mada University Press. Yogyakarta.

Voight, R. 1995. Buku Pelajaran Teknologi Farmasi. Diterjemahkan oleh S.N. Soewandhi. Edisi V. Gadjah Mada University Press. Yogyakarta

Yuliani, N. N., Sambara, J., \& Mau, M. A. (2016). TEST ACTIVITIES ANTIOXIDE ETILASETAT FRAMES OF ETHANOL EXTRACTS RED GINGER RANGE (Zingiber officinale var Rubrum) WITH DPPH METHOD (1, 1-Diphenyl2-Picrylhydrazyl). JURNAL INFO KESEHATAN, 14(1), 1091-1111. 